\title{
The Analysis of Key Competence of Industrial Cluster of Rare-Earth in Gannan
}

\author{
Shanqing Liu, Zhenyu Xiong, Xiaodan Zhu \\ Business school, Jiangxi Normal University, Nanchang, 330022, China
}

\begin{abstract}
The thesis comprehensively apply on the study of literature and the way of comprehensive analysis. It focuses on the key competence of industrial cluster of rare-earth in Gannan. The thesis holds the view that industrial cluster of rare-earth in Gannan had formed the dimension nowadays, but it's key competence need to improve from these aspects of key technology, the strategy of industrial cluster, marketing, key management, trademark and control of crisis to improve constantly in order to make the industrial cluster of rare-earth in Gannan develop well.
\end{abstract}

Keywords-key competence; industrial cluster; rare-earth of Gannan.

\section{INTRODUCTION}

In recent years, with development of economic globalization, the rare-earth that is vital strategy of recourse had been applied more extensive. But for a long time, the level of technology of is very low in industrial cluster of rare-earth. The capacity of primary product is surplus and the problem of low price is more prominent led to the rare-earth can't play important effect in our economic development. Jiangxi province contain abundant resources of rare-earth which is mainly concentrating on south of Jiangxi. This thesis attempt to evaluate the key competence of industrial cluster, to research the problems of existence and to put forward some the counter plans to improve the competence of industrial cluster.

\section{THE BASIC SITUATION OF INDUSTRIAL CLUSTER OF RARE-EARTH IN GANNAN}

The beginning of industry of rare-earth in Gannan is late, but it developed rapidly and has built the complete industrial cluster of rare-earth which formed the system from mining, smelting. And the technology applying on deep cure and foreign trade. The industry of rare-earth became one of the mainstay industries in Ganzhou. According to the statistics of the City of Industry and Information Commission, the rare-earth of large-scale company have 28 companies in Ganzhou, including the bloc of Ganzhou rare-earth, the company of technology in south of Jiangxi, the company of Qaindong in Ganzhou. These companies have become important enterprise in China. The value of production of rare-earth has surpassed 50 billion Yuan. And the income from main operation had got 26.7 billion Yuan. The industry has achieved the profit about 12.6 billion Yuan. Moreover, the south of Jiangxi province becomes the largest basement of production in our country.

The association of rare-earth has been set up in Ganzhou on December $18^{\text {th }} 2007$. Its aim is coordinating and improving the development of industrial cluster of rare-earth in Gannan. These regions where distribute the concentrated recourse of rare-earth such as Longnan,
Dingnan and so on, have set up the Bureau of Mines to develop the local mining and to ensure these companies to run orderly.

In 2012, the ministry of technology formally approved the establishment of Ganzhou Rare Earth Group Ltd., Jiangxi University of Technology, Ganzhou Institute of Nonferrous Metallurgy which is national units based ionic rare earth resource efficient development and utilization of engineering and technology research center, the National R \& D platform for rare earths establishment, will greatly promote the upgrading of industrial clusters Gannan rare technological innovation capability.

At the same time, southern Jiangxi Rare Earth Industry Cluster, there are still some serious problems, mainly reflected in: a serious loss of rare earth resources, deforestation mining unorderly are very prominent in some areas, illegal mining has led to excessive exploitation of rare earth waste of resources. The advanced application of Rare earth industry developed slowly, lack of technological innovation, the poor level of deep processing, making rare earth products are mainly concentrated in the low-end market, low value-added products and resource efficiency is not high. Overall industrial clusters of small-scale, low industrial concentration; there is not a better formation of scale, the overall lack of competitiveness. ${ }^{[1]}$

\section{ANALYSIS OF RARE EARTH INDUSTRY CLUSTER CORE COMPETITIVENESS IN SOUTHERN JIANGXI}

The core competence is a complicated systematic project, which is based on the core technology of a competency-based multi-level, multi-angle construction, the specific performance of eight kinds of capabilities: the core technology capabilities, core marketing capabilities, core brand image capability, core service capabilities, production capacity of the core, the core management skills, the ability to respond to strategic decision-making ability. ${ }^{[2]}$

After decades of development, southern Jiangxi Rare Earth Industry Cluster now has a certain size, but still needs to improve, to become bigger and stronger Gannan rare earth industry clusters, it must enhance its core competitiveness, and only truly "human no one I have, I have excellent ", to be invincible in the fierce market competition. Core competencies are scarce and irreplaceable; it is difficult to imitate others. This paper intends to use these core competencies specific analyses of the core competitiveness theory Gannan rare earth industry clusters.

\section{A. The capacity of Strategic decision}

The ability of the strategic decision determine industrial clusters on their strengths, weaknesses, opportunities and threats of cognitive and grasp, the right direction for the development of the selected. For a long 
time, the major strategic decision of Gannan rare earth industry clusters have become more passive, over-reliance on government planning industry, industrial cluster itself is not enough to grasp the degree of the market, such as: they do not know their own macroeconomic strategy of development, don not clear the direction, and plan of industry development not very clear, throughout the development of the industry fails to co-ordinate and so on.

\section{B. Core technical capabilities}

Industry clusters of Gannan rare earth have the advantage in terms of mining and milling in heavy-iontype rare earth primary products, the industry's technology is advanced in the domestic counterparts. However, the industry cluster of Gannan rare earth needs continuous to strive in the rare earth deep processing. The advanced application of rare earth products also rests in the hands of foreign companies, which for southern Jiangxi Rare Earth Industry to enhance the core competitiveness of clusters is very unfavorable.

\section{Core marketing capabilities}

The industry cluster of Gannan rare earth relatively does not build a complete marketing network; the trend of product sales is very passive, subjected to state regulation rather than market prices, the advantages of the concept of market-oriented operation is relatively weak. But in recent years as the country restricting the supply of primary products of rare earth, rare earth export prices generally rise; it also gives rare earth industry cluster Gannan brought greater benefits

\section{Core brand image capability}

The image of corporative brand is a huge intangible assets, in recent years, the industrial cluster of Gannan rare earth integrate the enterprises through the integration of industrial clusters and have been established on several large-scale enterprises, such as: In 2008, the central enterprises Minmetals and Jiangxi South co-founded two companies Minmetals rare Earth rare Earth (Ganzhou) company, which now has 15,000 tons / year of separation ability. However, similar companies today are "big but not strong."

\section{E. Core service capability}

Recently, Gannan Rare Earth industry cluster posse and advantage in pre-sale service, which is able to provide detailed introduction of products elaborate comparison between them. It doesn't demand a high -level after -sale tracking service for the reason that the product we sell is resource-oriented

\section{F. Core production capacity}

Level of core competencies needed to show through products, industrial clusters in southern Jiangxi Rare Earth ionic rare earth separation of primary production sectors do well. Annual production capacity has reached tens of tons, but production will make long-term excessive depletion of natural resources. In 2011, southern Jiangxi Rare Earth Industry Cluster had faced no mineable ore situation.

\section{G. Core management capabilities}

Enterprise management is also productive, efficient management can create great wealth for the enterprise. Because of national policy, southern Jiangxi Rare Earth Mining industry cluster resource management and other aspects of the increasingly standardized. Enterprise rare earth industry cluster has praiseworthy in their own management areas: the confidentiality of such technology, the production process rigor. However, in terms of organizational structure, there are still some problems, some companies' administrative culture "thick, most of the companies in order to immediate, ignoring more details.

\section{H. Response capability}

Southern Jiangxi Rare Earth Industry Cluster face many changes, including the external environment, including, did not form part of their unique ability to respond to respond to the crisis. The face of potential threats (such as 2010 Japanese progress in some rare earth oxides alternatives developed areas) is poor awareness ${ }^{[3]}$

\section{ANALYSIS OF PROBLEMS IN GANNAN RARE EARTH INDUSTRY CLUSTER OF CORE COMPETENCE}

\section{A. "Various of policies" lead to the extreme unclearness in the developing and planning of industry}

Unclear develop of industry and no planning as a whole of development state of the industry are the two major problems. Due to history, companies of Gannan rare earth once belonged to different sections. Although, in recent years, rare earth industry cluster was planned by local government, it was also inevitably affected by other upper directed institution. The government planning is always macroscopically in the rare earth which will be easily led to unclear development in cluster of industries. What's more, local government only considers his own benefit and each does things in his own way, which can be easily caused to a situation that a huge waste of resources and low efficiency in the development of rare earth industry may happen.

\section{B. "Internal and external difficulties" leads to lack of creation in intensive processing of cluster of industry}

It has two major problems, one is insufficient creation of intensive processing of cluster of industry, and the other is poor ability in core technology. [4] Insufficient creation of intensive processing of cluster of industry results from monopoly of relative technology in abroad and the company itself do not pay attention to its development. Many enterprises are engaged in rare earth smelting and refining separation of primary products, and in the rare earth products' deep processing of application of rare earth downstream of the industrial cluster operations are stagnant. In comparison, the downstream processing application technology investment costs a huge amount of money, long cycling, slow effectiveness, high risk, which makes them be reluctant to spend a lot of resources in this respect, most companies want to adopt "rapid spike" return on investment process. In the long run, it will go against the core technology in the field of deep processing of rare earth industry cluster. 


\section{C. "Sell passively" makes a single marketing network channel}

Still need to broaden the marketing network channels, product sales is still on primary products. For a long time, Jiangxi rare earth industry cluster marketing network channel is unitary, because of resource-based industries, industry cluster in marketing is often passive, generally is asked by the customer the product price, the consciousness of enterprises lack of initiative to widen marketing channels. And most of the sales product is given priority to primary smelting products, which does not have the price advantage and cannot create additional profit.

\section{Large enough to affect the corporate brand scale industrial clusters}

Gannan rare earth industry cluster is currently no international influence with large enterprises, the lack of industrial clusters brand relevant enterprise "brand" recognition is low. Large enterprises in clusters in some key areas do not have a pivotal role in industrial scale is not obvious, the lack of core growth pole.

\section{E. Administrative management and make a quick buck in clusters of enterprise management efficiency is not high}

Most of the enterprises are state-owned enterprises in the industrial cluster, there are still some "bureaucratic" style within the enterprise, the impact of enterprise management efficiency. In the upstream mining and milling companies, mostly chase immediate, extensive economic growth mode obviously, pay attention to corporate governance, not pay attention to all aspects of the business to improve optimization.

\section{F. "Scarce resources" Let's industrial clusters lack a sense of crisis}

Lack of industrial clusters sense of crisis, can not effectively deal with potential threats now, southern Jiangxi Rare Earth Industry Cluster ions with heavy rare earth resources in this unique advantage in this field with a strong competitive edge, but over-reliance on resource scarcity also allows a high degree of industrial clusters lack a sense of crisis, so that effective measures to deal with the crisis and there is no way to build a potential threat. Once the short encounter similar threats by the blow may be fatal.

\section{THE PROPOSAL OF FURTHER ENHANCEMENT TO THE CORE COMPETITIVENESS OF INDUSTRIAL CLUSTERS OF RARE-EARTH IN THE AREA OF SOUTHERN JIANGXI PROVINCE.}

Through a comprehensive analysis of industry clusters of rare-earth in southern Jiangxi, the author worked over a rich supply of literature, field research and combined to expertise for further enhancement to the core competitiveness of industrial clusters of rare-earth. Here are some proposals which probably contribute to the industrial clusters related.

\section{A. To formulate the plan of developing the industry of rare-earth}

The local government must formulate the plan of developing the industry of rare-earth and boost the ability of strategic decision-making. The government must work to an industrial plan of rare-earth related in coordination with rare-earth businesses. The development and implementation of all policies must be applied to the local systems and industrial clusters. Also it must help to concentrate rare-earth businesses and be conducive to extend the industrial chain and the development of industrial clusters. The general developing strategy of industrial clusters across the region needs a further overall planning for eliminating the phenomenon of "fragmentation”. Meanwhile, the top-layer design cannot be separated from the practical condition of the industrial cluster of rare-earth. Only with right orientation and strategic planning can industrial clusters expand in the right direction for a better enhancement to its core competitiveness

\section{B. To enhance the core technology capabilities}

Rare earth mining and moiling companies in the south of Jiangxi province should improve the core technology capabilities all-dimensional and build the core competitiveness of the foundation so that they can maintain a competitive advantage in the industry, maintaining the advanced position and the reliability of the companies. The companies which endeavor to the deep-processing application of rare earth should try to enhance their own technical capacity, to strength technological innovation and to increase research investment. Besides the government can offer more support, share and reduce the cost risk of technological upgrading and transformation of enterprises, vigorously promoting the rare earth deep-processing technology innovation to help build up the industry clusters. Government should make good use of all resources, such as we can mobilize and integrate the research advantages of the parties, the core technology to enhance all-round ability to maintain technological superiority on the platform of rare earth ions national resource efficient development and utilization of engineering and technology research center [5]

\section{Continues to build up and improve the core marketing capabilities}

It's vital important for company to change the technology for business advantage into market advantage via building enterprise marketing network channels and expanding marketing channels. Southern Jiangxi Rare Earth Industry Clusters not only need to continue to keep the traditional primary products of rare earth export market but also to expand the export market of deep processing rare earth and application products and finally build the diversified product market to meet the domestic and international market-oriented and demand for different products. The companies also needs to focus on developing high value-added rare earth products market and further improve the marketing capability of industrial clusters. 
D. Set up the leading enterprises, and build the ability to assemble industrial Brands.

In 2008, the central Minmetals enterprise cooperated with two rare earth Industry in Gannan to establish the Minmetals Rare Earth (Ganzhou) company, which now has the separation ability of 15,000 tons / year. [6] Rare earth integration can effectively curb illegal mining of rare earth; rare earth industry cluster integration is also conducive to the protection of rare earth resources, and the improvement of rare earth prices.

We should rely on government support policies, develop leading enterprises, industries, and create the ability of enterprises brand, and then turn it into a competitive advantage. To develop large enterprises such as Ganzhou Rare Earth Group, this has greater comprehensive ability, deep development potential, to create the "star business" in industrial clusters and forming brand competitiveness.

\section{E. Make leading enterprises, the ability to create industrial cluster brand}

Industrial cluster is composed by different enterprises and composition. Industry cluster core competitiveness is the key to any natural development of enterprises. Enterprises should strengthen the organization and enhance management capabilities. Note that with the industry to conduct a comprehensive comparison of businesses to identify their own deficiencies in the management and developers, and propose specific targeted measures to strengthen corporate organizations, to enhance and improve on aspects of business, including production, services, etc., integrated management capabilities.

\section{F. Build capacity to deal with the crisis response}

Faced with fierce market competition, industry cluster must always remain sober, to build and threats of immediate response to the crisis response capabilities and defense capabilities in order to ensure that the overall business advantage. In addition, should the rational allocation of resources, industrial clusters, will tilt the important internal resources to key sectors, pay attention to the introduction of professional and technical personnel, the implementation of the core competitiveness of talent as a prerequisite for protection.

\section{CONCLUSION}

Through the use of literature survey, a comprehensive evaluation and analysis and other methods, combined with the strategic management of industrial clusters. Core competence theory, a detailed analysis of Gannan facing rare earth industry cluster strengths and weaknesses, and the paper also check the recent government support policies Gannan rare earth industry clusters and build the core competitiveness of industrial clusters, extending the rare earth industry chain, and stronger measures to rare earth industry cluster, and analyze comments, combined with the expertise I have learned, made a number of recommendations for stakeholders' reference.

With the implementation of the plan to revitalize the Soviet Gannan rare earth industry cluster is facing rare opportunities for development. We should make full use of resources, grasp the policy an opportunity to strengthen the integration of resources, increase research investment, and actively develop rare earth deep processing and highend industrial applications, and effectively carry out technical transformation and innovation. Only in this way can the resources of rare earth into Gannan technical and economic advantage. To actively cultivate Gannan rare earth industry leading industry clusters, Gannan build the core competitiveness of industrial clusters of rare earth, rare earth let Gannan Central Soviet industrial clusters become a focal important engine of economic growth, as well as a major development in Jiangxi China's rare earth industry to make due contributions.

\section{ACKNOWLEDGEMENTS}

The research work was supported by Jiangxi Provincial College of Humanities and Social Science Research Projects Fund under Grant No. GL 1325 and by Jiangxi Provincial Academy of Social Sciences Plan Project Fund under Grant No.12GL35.

\section{REFERENCES}

[1] Research Cluster Development Strategy Yang Jiedeng. Southern Jiangxi Rare Earth Industry [J]. Rare, 2009,30 (5) :26-29.

[2] linghanchuan and other SME management (second edition) [M] Beijing: Higher Education Press,2011:276-280

[3] Liu hong.Strategy Jiangxi Rare Earth Industry cluster development under the new situation - in J's case [D] Master thesis Nanchang: Nanchang University, 2012.5 [4] Xu Tian new. Gannan rare earth industry SWOT analysis [J]. Cooperation in economy and technology, 2013,3 (total 460)

[5] Xie Mansheng. Enhance the core competitiveness of Jiangxi Rare Earth Industry [N]. Gannan Daily .2014.1.21

[6] Zhong Zhimin earths list large group emerged [N]. China Securities Journal. 2014.1.7 